Author: Stephen Corbett

Word Count: 5658

Affiliation: School of Education \& Childhood Studies, University of Portsmouth, 141 High Street, Portsmouth, PO1 2HY, UK

Email: Stephen.corbett@port.ac.uk

Telephone: 02392845215 


\title{
From teacher to manager: expectations and challenge in the further education sector. A relationship model.
}

\begin{abstract}
In a turbulent working environment with varying expectations and challenges is it fair to expect further education teachers and managers to maintain and improve standards? This article highlights that with the incorporation of colleges began a series of initiatives to professionalise the FE sector. This coupled with pressures for those who work within it to meet KPIs in a climate of financial constraint and inconsistency of policy decisions led to a culmination of challenges. By reviewing current literature the article goes on to suggest that a conceptual shift in our thinking about teachers and managers based within the further education sector is necessary; one that considers the parallels in the two roles and the similarities in the expectations and challenges of each. This could considerably assist our understanding of the commonalities between these roles, and that instead of discussing teachers and managers as separate and seemingly opposing forces, it will develop a teacher-manager relationship model. This model creates an opportunity for further research to build upon to either; consider how the roles may seek a collegiate response to challenges or; how the gap in expectations may be narrowed.
\end{abstract}

Keywords: Further Education, Teacher, Lecturer, Middle Manager, Manager, Challenges, Expectations, England 


\section{Introduction}

This article focuses on the further education (FE) sector based in England. The remit is restricted to further education colleges and training providers, who are funded via the Skills Funding Agency (SFA), Education Funding Agency (EFA) and, in the case of sixth form colleges, the Department for Education (DfE); the article does not consider universities. It is felt this is an important distinction as research into practices in FE are somewhat limited when compared with other strands of education such as primary, secondary and higher education.

The 1992 Further and Higher Education Act released FE providers from local authority control and required to become freestanding public bodies known as further education corporations or sixth form college corporations. With the incorporation of FE colleges came about a requirement for the sector to be professionalised in order to raise standards. This article aims to review what is expected of FE teachers and managers as well as the challenges they both face. Through critical analysis of existing literature this article presents a teacher-manager relationship model which illustrates the parity and discourse in expectations and challenges for both roles. It is anticipated that this model could be used to consider future research into the area of supporting FE teachers and managers.

The FE sector services a range of student educational needs categorised in a range of ways. Broadly FE providers categorise students in terms of age as this has the greatest variance in terms of funding sources i.e. SFA or EFA. According to statistics published by Association of Colleges (AoC 2016) 2 million adults aged over 19 and 773,000 16 to 18 year olds participated in government funded college-based, further education in 2014/15. In addition to these figures are students with Special Educational Needs or Disabilities (SEND) who also undertake study in FE providers. In order to service the demand for wide ranging academic and vocational curriculum the FE sector needs to attract and retain good quality teachers who are managed by competent and confident managers. While there are not labour demand and supply figures specifically for the FE sector, the Department for Business Innovation and Skills reported that the sector was finding it difficult to recruit suitably qualified teachers (BIS 2014). In a wider analysis of mainstream education the National Audit Office reviewed the number of teachers in-post and in-training; it highlighted 'teacher shortages are growing' (2016). These studies show the number of those wishing to work as teachers, and who could then become middle managers is being eroded, potentially this is due to a declining appeal to work within the education sector; something that this article will discuss

In addition to potential labour supply challenges, the FE sector has undergone a series of cuts in terms of it funding. According to the AoC (2014) between 2010 and 2015 there was 12\% real terms cut in funding and there have been no increase in funding since 2010 for pay rises, 
which limits the sector to be competitive in terms of pay and invest in resources to deliver provision. Most recently BIS (2015) published a framework to review post-16 education and training. This review incorporates a structural review of current further education providers so that they are able to operate with a tight fiscal environment (BIS 2015). This combined with media speculation that $40 \%$ of sixth forms and general further education college could close (Independent 2015), provides an unattractive climate of anxiety and uncertainty. Therefore, FE leaders need to develop organisational strategies to survive and succeed, these are translated by middle managers and delivered by FE teachers. The operationalization of these strategies in a difficult environment will inevitably result in challenges faced by the job holders. This article will review these challenges.

\section{Method}

A literature search was completed using characteristics of what Bryman and Bell (2015) would term systematic review; the rationale being to provide focus of literature sourced while attempting to limit research bias. The search was structured to filter results combined with a clear set of criteria for each article used. While the search method has characteristics of systematic review, a method aligned strongly with scientific research, this research paper is primarily inductive as it seeks to build theory from existing literature (Saunders, Lewis, and Thornhill 2007).

The search was administered via the EBSCO database with an aim to develop an understanding of the current theoretical perspective in relation to the expectations and challenges of both teachers and managers in the further education sector. The search parameters were limited to peer reviewed academic journals that have been published in the United Kingdom from 2000 onwards. While this provides a potential limitation in terms of validity as some articles may be outdated, the field of research is such that to exclude older articles could be to the disadvantage of this article. Similarly, in the first instance keywords were cross referenced with 'further education' to filter out literature for other sectors in education such as secondary and higher education, however, it could be suggested that the scope of research was too limited. Therefore the parameters were broadened to enable consideration of lessons learnt in other UK educational institutions. Table 1 provides an illustration of the search framework used and the number of results per search.

Key words searched: further education, teacher, teacher development, manager, manager development, expectations and challenges.

\section{Table 1 - Search Outputs}




\begin{tabular}{|l|l|}
\hline Further Education & 798 \\
\hline Further Education AND Teacher & 270 \\
\hline Further Education AND Teacher AND Expectations & 41 \\
\hline Further Education AND Teacher AND Challenges & 63 \\
\hline Further Education AND Teacher Development & 9 \\
\hline & \\
\hline Further Education & 798 \\
\hline Further Education AND Manager & 118 \\
\hline Further Education AND Manager AND Expectations & 59 \\
\hline Further Education AND Manager AND Challenges & 74 \\
\hline Further Education AND Manager Development & 9 \\
\hline
\end{tabular}

Once the searches were complete the articles were reviewed and short listed to determine those whose content would apply to this research. There were three core criteria, an article must meet one of these criteria be considered:

1. The article would provide clarity of either expectations or challenges for teachers in the FE sector

2. The article would provide clarity of either expectations or challenges for middle managers in the FE sector

3. The article would provide context of the environment in which both the role of teacher and manager are operating.

\section{Findings}

This section provides a narrative on the context of the FE sector. It highlights key milestones which have shaped the sector and directly impacted on the professionals which operate within it. It will then focus on the expectations and challenges of teachers in FE before considering the expectations and challenges of FE middle managers. Finally it will consider the potential similarities between the challenges faced by both roles and present a teacher-manager relationship model for these expectations and challenges.

\section{Context of a Professional Further Education Sector}

There are various studies which refer to the professionalization of the FE sector (Lucas 2013, Bathmaker and Avis 2013, Simmons and Thompson 2008, Avis 2005). These studies consider the impact of government policy and the introduction of more rigorous external quality assurance. Some studies go further to review the mechanisms used to enhance the sector's performance, such as Lucas, Nasta \& Rogers (2012) who discuss the introduction of 
organisational standards while others, such as, Forrest (2015) review the effectiveness of external quality assurance agencies like Ofsted in improving standards. Each of these studies provide a context in which FE teachers and managers are operating. In 1992 FE colleges became incorporated and were released from local authority control, not dis-similar to the current proposed academisation of schools in the UK. Post incorporation, standards in the FE sector were inconsistent and so began the professionalization agenda for further education. It can be argued that this agenda is yet to be finalised as there have been several iterations including the introduction of Further Education National Training Organisation (FENTO) Standards in 1999, followed by Lifelong Learning United Kingdom (LLUK) Standards in 2006 to the present day Education \& Training Foundation's (ETF) Professional Standards for FE Teachers \& Trainers which were published in 2014. In parallel with the indecisive approach to setting professional standards the sector has experienced fluctuations in expectations of teachers' training. In 2001 new regulation was introduced which required all FE teachers to be suitably qualified to support their students. This was then reaffirmed in 2007 when, depending on their role, FE teachers were expected to possess a specific teaching qualification. However, in 2013 the requirement to possess a teaching qualification was revoked. Though, the Department for Education (2016) does highlight there is a general expectation and value given to FE teachers possessing a good teaching qualification.

The aforementioned mentioned professional standards were published with a focus on teachers' standards. While there are implications for managers, there are no distinct expectations of professional standards for FE managers, other than that of generic management standards such as those published by bodies like the Chartered Management Institute (CMI). Evidently even if they did, with continual fluctuation in expectations of FE teachers it would be highly doubtful managers should expect to have any greater level of consistency of expectation.

\section{Expectations \& Challenges of Further Education Teachers}

The variation in professional standards has also required initial teacher training to be continually updated. Teacher educators will resonate with these changes, some core qualifications titles have remained, such as the PGCE and Cert Ed, though there content is quite different today compared with 17 years ago when the FENTO standards were published. This is because as external expectations have also changed and therefore so has the content of initial teacher training. Factors to be considered when designing initial teacher training include professional standards, Ofsted common inspection frameworks and wider government policy; all of which are subject to continual update and change. Qualifications such as PGCE and Cert Ed are associated with universities. However, there are also qualifications that can 
be undertaken through other awarding bodies such as City \& Guilds and Pearson, which are subject to greater government intervention as they are validated via the Qualification Curriculum Authority (QCA). Veteran teacher educators will recall qualifications such as, Further Adult and Teachers Certificate (FATC) stage 1 and 2. These qualifications were reformed into Preparing to Teach in the Lifelong Learning Sector (PTLLS) and associated progression routes such as Certificate and Diploma in Teaching in the Lifelong Learning Sector (CTLLS \& DTLLS) which have now become Award, Certificate and Diploma in Education and Training (AET, CET and DET). These latter qualifications are currently subject to review again.

As FE colleges offer a broad range of both academic and vocational courses many FE teachers originate from industry. The requirement for an FE teacher to have strong subject knowledge and industry expertise results in many moving into teaching later in their work career. This requires a shift in their professional paradigm, from that of their industry to that of a teacher. The midcareer change often means many are unable to undertake a full time preservice initial teacher training course. Instead they gain employment as a teacher before training as one. This results in completion of their initial teacher training on a part-time basis alongside their teaching role. Orr \& Simmons (2010) emphasise a key challenge for FE teachers through the dual lens they possess, in particular during their initial training phase. The dichotomy presented is that they are a trainee teacher who is expected to perform as a qualified teacher. This presents multiple challenges, firstly that of competence; as a new teacher you are developing you pedagogic practice, this is often a sustained developmental process which takes time and therefore it is unrealistic to expect a new teacher to perform in the same way as a seasoned teacher. The second challenge is that of identity, Page (2013b) studied the transition of trade professionals into FE teaching. In his study he highlighted the stark contrast between a person's initial trade and the role they are moving to. While his findings suggest the transition is not as difficult as one might initially perceive it to be, there is a need for 'cognitive reconstruction' (Page 2013b) to adopt the new identity of teacher. According to Orr and Simmons (2010) $90 \%$ of trainee FE teachers complete their training via a part-time in-service programme, therefore this challenge affects a significant proportion of new teachers. For those who enter via a pre-service route there are also challenges, Bathmaker \& Avis (2013) found that like their in-service counterparts pre-service trainees can find themselves needing to adapt to the culture of teaching in FE.

The affor mentioned studies (Bathmaker and Avis 2013, Orr and Simmons 2010, Page 2013b) provide a good insight into the challenges faced by those new to FE teaching. Unfortunately the challenges do not end with completion of a teaching qualification. In Hodkinson's (2007) study, based across 4 FE colleges, he concluded on two pressures which impact on teachers; 
inadequate funding of resources and what Walsh (2006) describes as educational bureaucracy led by management. Essentially these pressures lead to FE teachers focusing their time and energy on overcoming barriers and filling in paperwork rather than focusing the learning process of their students. Teachers who do not wish for their students to be disadvantaged often disadvantage themselves, through overwork, to ensure their student needs are met. The reality is that in a time of austerity the workload of teachers is increasing both in and outside of the classroom (Simmons and Thompson 2008). Furthermore, funding cuts and austerity can manifest into what O'Leary \& Smith (2012) describe as a 'Culture of Fear'. These factors are undoubtedly contributors to the turnover rate of teachers in FE, which is higher than the sector average rates published by the ETF $(2014,2015 a)$ in both $2012 / 13$ and $2013 / 14$, though there was a marginal improvement in 2013/14 there are still national shortages of teachers (NAO 2016).

Overall FE teachers, like their counterpart in other areas of the education sector, encounter many challenges. It would be difficult and not practicable to conclude on one key challenge that all FE teachers face which should be eliminated. However, the studies analysed in the article do suggest that the high expectations of early career teachers combined with limiting resourcing in a climate of ever changing expectations could result in a loss of FE teachers. With reported national deficits in the supply of teachers (NAO 2016), creating an environment which can result in unnecessary loss of teachers is not conducive to the needs of the education sector.

\section{Expectations \& Challenges of Further Education Middle Managers}

The incorporation of colleges in 1992 meant that business functions became the responsibility of each institution. Leader (2004) discusses the implication for structural change and the emergence of FE middle managers who adopted what O'Leary \& Smith (2012) describe as a private sector managerialist approach. Both Thomson \& Wolstencroft (2015) and Leader (2004) explain that FE middle managers translate strategic vision into day-to-day activities and ensure organisational policies are adhered to. While this expectation seems standard to that of any other middle manager it should be noted that this post-incorporation transition was not without its challenges. The newly adopted business approach by college managers which was driven by performativity measures and a need to meet funding linked targets led to high staff turnover and according to Simmons \& Thompson (2008) a demoralised workforce. Avis (2005) also highlighted the discourse in early management practice, where performance management led to perceptions and accusations of bullying and a blame culture. Both Avis (2005) and Thomson \& Wolstencroft (2015) suggest that an influx of female managers may have helped to reduce occurrences of intimidating management practice and was responsible 
for the feminization of management in FE. It is not simply the behaviour of managers which comes under scrutiny, while his study was not specific to FE, Walsh (2006) argues that a further challenge for educational managers was the over reliance on bureaucracy which came as a result of strategies to improve quality and standardise curriculum. This led to managers adhering to systems and procedures to produce outcomes and thus seeing students as statistics rather than people.

It can be easy to pass negative judgement on managers, however, is it fair to do so? Are the expectations of an FE middle manager as changeable as that of an FE teacher? Briggs (2001) explains that the job role of FE middle managers is to translate the expectations of their line managers into actions for teaching staff to complete; thus being a transactional function. However, more recently Beresford \& Michels (2014) discuss that the role of FE middle managers has become far greater than transactional. The need for FE managers to act as industry entrepreneurs is seemingly more important given the continual reforms to curriculum, funding and quality assurance that the FE sector experiences. If middle managers are unable to respond and react with innovative methods to drive recruitment, meet Key Performance Indicators (KPI) and retain the best staff, their departments and consequently their organisations could go into decline. Building on this, Leader (2004) emphasises the value of allowing middle manager to shape vision and strategy, rather than them simply being a used as a tool for its implementation. Due to the potential shortage in educational leaders it is essential to develop middle managers into strategic visionaries (Lambert 2012).

It is the responsibility of FE middle managers to ensure strategy is implemented and manage operational activities, both of which are concepts similar to standard definitions of middle managers. However, does this present a dichotomy for those within the role? As many FE middle managers were teachers once, it is doubtful they are ignorant to the challenges faced by their staff. If we were to apply Orr \& Simmons (2010) dual lens to first time FE managers we view it as a teacher being expected to fulfil the role of a manager; which role does the individual see as first and foremost? This article has reviewed the range of ever changing standards for FE teachers, coupled with the different teaching qualifications which are all designed to ensure FE teachers are capable and competent teachers. It cannot, however, do the same for FE middle managers. There are no current professional standards or suggested training programmes other than generic management development. Furthermore, there is no requirement or expectation for first time FE managers to undertake training and according to a study by Thompson \& Wolstencroft (2015) when they do receive training it does not align with their development needs. Yet they are expected to assume the role of manager immediately, not dis-similar to the dual lens challenge discussed by Orr \& Simmons (2010) for new trainee teachers, who are expected to perform as qualified teachers. 
Stressors faced by what Page (2013a) terms as First Time Managers (FTMs) can play a key part in how the dichotomy is managed. Whether it is being overworked, under trained or coping with the operational activities Page (2013a) concludes that either FTMs develop coping strategies or they will leave. The ETF (2014) report on 2012/13 staff turnover rates showed FE middle manager turnover was lower (at 15\%) than that of teachers. This could be because the majority of managers would have formerly been teachers and therefore those wishing to leave the sector would have done so at the teacher stage of their career. Another possible reason is suggested by Weston (2013), who states that after their fourth year of service $80 \%$ of teachers take on additional duties which are managerial in their nature due to a lack of other methods to recognise their teaching "prowess". This is not a new concept as both Purvis (1973) and Sikes (1985) explain that career progression within teaching can be fairly limited in most educational organisations, not just further education institutions, as the organisational structure for teachers to progress is relatively flat. There are differing opinions as to why teachers assume management roles, for example, Evett (2002) implies that some teachers take on managerial positions to accrue more administrative time to carry out their increasing list of duties. Whereas, Thompson \& Wolstencroft (2015) believe a management position may be the only way for a FE teacher to increase their salary.

Overall, FE middle managers are confronted with challenges, in particular when first taking up their role. Middle managers have no professional standards, expectations or clear guidance on how to conduct themselves or what their role will entail other than translating the strategic vision into an operational reality. This could result in an inconsistency of expectation from one college to another, meaning the middle manager will need to know their organisation well in order to perform their duties effectively. The lack of relevant training as highlighted by Thompson \& Wolstencroft (2015) coupled with the sink or swim mentality suggested by Page (2013a) leads to a potential conclusion that FE middle managers are less supported than FE teachers in taking on their role, however, in parallel with teachers only the resilient will remain.

\section{Teachers and Middle Mangers}

These two roles of often seen as distinct separates, and in some organisations, potentially as opposing forces; one blaming the other for negative impacts on their own role. However, both roles have needed to adapt and often without clear parameters in how to do so. This is especially the case for those new in role; trainee teachers being expected to mirror their more experienced counterparts and adopt a new professional identity (Page 2013b). New managers being expected to complete their responsibilities even though certain concepts of management are foreign to them as teachers (Thompson and Wolstencroft 2015). Both roles operate in a challenging work environment which is target focused and subject to external 
quality assurance measures. This coupled with austerity measures which limit resourcing and therefore mean that initiative is needed in how to best support students. This results in both roles having high workloads to ensure targets are met and standards are maintained or raised; which will result in high levels of stress as suggested by Page (2013a). The reasons for this stress, such as, under developed competencies and high workload while attempting to develop a professional identity are applicable to both roles.

Using relationship modelling, the parallels and distinctions between the challenges and expectations for each role become apparent. Figure 1 shows a relationship model of the challenges and expectations discussed in this article. The model plots challenges (black spheres) and expectations (white spheres) against a continuum of both roles. The size of the sphere suggests the scale of impact the item would have on the roles it is aligned to. The model is zoned to show which factors are exclusive to each role and which are shared.

\section{Figure 1 - Teacher-Manager Relationship Model ${ }^{\circledR}$}

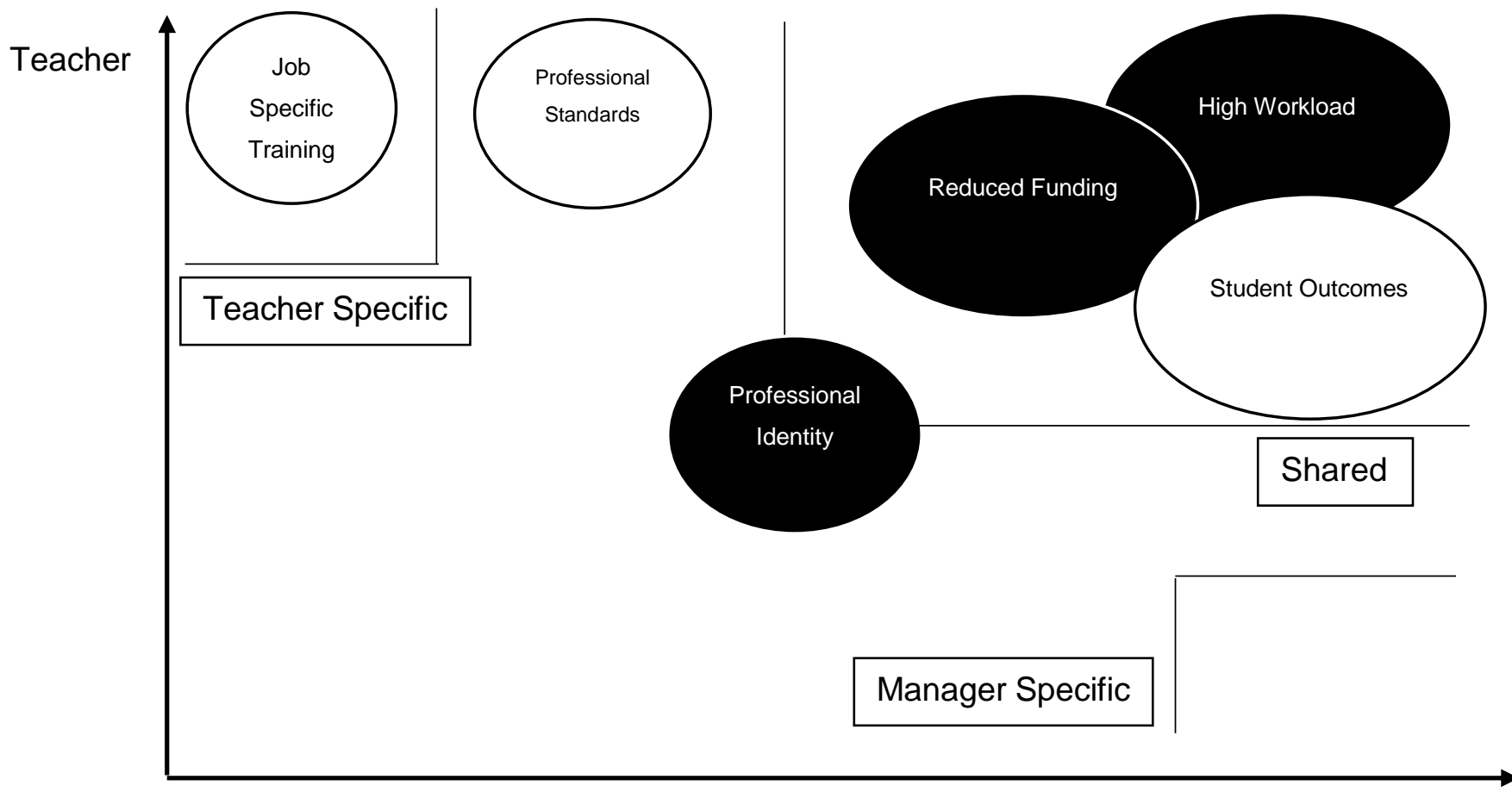

Manager

The most significant factor in terms of expectations is student outcomes, which is an indicator of performance i.e. success rates, value added and progression; this is a shared expectation of both roles. This can be seen in two paradigms; the administrative function of their role in meeting KPIs and external stakeholder expectations, and, the implicit motivation to ensure 
students are successful. These points are discussed in varying degrees by authors such as, Beresford (2014); Briggs (2005); Leader (2004); Bathmaker \& Avis (2013) and Simmons \& Thompson (2008). Regardless of the paradigm, student success is a fundamental expectation for both roles. The second expectation, professional standards, are shown closer to the teacher specific region. This is not to suggest managers are not professional, instead it highlights the lack of FE manager specific professional standards compared to FE teachers who have clear published expectation in terms of the ETF (2015b) Professional Standards. The final expectation is that of job specific training, this is classed as teacher specific as there are no expectations for FE managers to undertake training for their role. While it can be argued this is also the case with the deregulation of FE teachers becoming qualified, there is still an implicit expectation for FE teachers to be trained. Furthermore, there are a range of specialist teaching qualifications for FE teachers to undertake from initial teacher training to subject specific pedagogical practice.

When reviewing the challenges of each role both share high workload and reduction in funding as significant challenges. The final challenge, professional identity, is also shared by both roles however due to the duality (dual lens) of the issue along with the challenge being at the early career stage of either role it is positioned centrally to each role.

There are two notable aspects of the teacher-manager relationship model (shown in figure 1):

1. The grouping of challenges and expectations. In particular the concentration of factors which are shared by both roles.

2. The absence of manager specific factors.

The role of teacher and that of manager can, at times, be viewed as opposing forces, which can also result in an 'us and them' culture. The Teacher-Manager Relationship Model seeks illustrates that while the roles are separate and distinct, they also have a shared set of expectations and challenges. This overview may be better utilised by both roles in order to understand the pressures of each and thus help to diminish cultural divides. Furthermore, it can provide guidance to those outside of these roles in how to best support them.

\section{Conclusion}

The article acknowledges common threads within the current theoretical perspectives. Many journal articles refer to the professionalization of FE and the impact it has had in terms of structural changes, new emergent cultures and ever changing expectations. There is also a belief that due to funding linked targets the initial management practice was highly business focused and a suggestion that this had a negative impact on some professionals in the sector (Avis 2005, Bathmaker and Avis 2013, Thompson and Wolstencroft 2015, Simmons and 
Thompson 2008). However, over time changes have occurred. There does appear to be a volatility of expectations for both teachers and managers. It also appears as if the sector has now become accustomed to a particular level of uncertainty. The business environment in which FE operates is ever updating and changing, this has meant practitioners who remain in the sector are becoming as Beresford \& Michels (2014) would describe as entrepreneurial. This said, I would expect many who work in FE would welcome a period of stability, unfortunately this seems unlikely in the near future with current spending and area reviews.

The further education sector in England has/is subject to continual change. In part, this was initiated by the incorporation of colleges in 1992, whereby FE providers were released from local government control and required to become freestanding public bodies known as further education corporations or sixth form college corporations. Since incorporation there has been a series of FE sector specific professional bodies including, Further Education National Training Organisation (FENTO), followed by Lifelong Learning United Kingdom (LLUK) to currently the Education \& Training Foundation (ETF). Each of these institutions have set out to professionalise and support FE providers in raising standards. This article has not set out to establish whether these initiatives have been successful. Instead it has discussed the resultant expectations and challenges for both teachers and middle managers in FE. It is clear to see that the challenges faced by each role have stark similarities, in particular; high work load, strategies to manage funding cuts and establishing their professional identity. In comparison expectations of both roles are not as closely aligned. It appears that expectations of FE teachers are somewhat clearer than that of managers. In particular with reference to professional standards and training that supports effectiveness in their job role. However, both roles are clear of the most significant expectation; student outcomes.

It is believed that by providing the teacher-manager relationship model, and a new lens through which to review the expectations and challenges of both roles. This also provides an opportunity or further research to consider how the roles may seek a collegiate response to challenges or; how the gap in expectations may be narrowed. While the model has been developed with the context of the further education sector in England, the principles of the teacher and manager roles may not vary greatly in other educational settings whether they differ geographically or by sector i.e. primary, secondary and higher education. If the model were applied to differing educational settings it could be worthy of note to consider the adaptations necessary for its application. 


\section{Bibliography}

AoC. 2014. College Funding and Finance. Association of Colleges.

AoC. 2016. College Key Facts 2015/16. Association of Colleges.

Avis, James. 2005. "Beyond Performativity: Reflections on Activist Professionalism and the Labour Process in Further Education." Journal of Education Policy 20 (2):209-222.

Bathmaker, Ann-Marie, and James Avis. 2013. "Inbound, outbound or peripheral: the impact of discourses of 'organisational' professionalism on becoming a teacher in English further education." Studies in the Cultural Politics of Education 34 (5):731-748. doi: 10.1080/01596306.2013.728367.

Beresford, Richard, and Nicolette Michels. 2014. "Embedding Change through the Entrepreneurial Role of Middle Managers in the UK Further Education Sector." Research in Post-Compulsory Education 19 (2):147-164. doi: 10.1080/13596748.2014.897505.

BIS. 2014. The Government's Strategy to Support Workforce Excellence in Further Education Department for Business Innovation \& Skills.

BIS. 2015. Reviewing post-16 Education and Training Institutions. Business Innovation \& Skills, Acessed 31 March 2016 https://www.gov.uk/government/publications/post-16education-and-training-institutions-review

Briggs, Ann R. J. 2001. "Middle managers in Further Education: exploring the role." Management in Education 15 (4):12.

Briggs, Ann R. J. 2005. "Middle Managers in English Further Education Colleges." Educational Management Administration \& Leadership 33 (1):27.

Bryman, Alan, and Emma Bell. 2015. Business research methods (4th Ed.): Oxford:Oxford University Press.

DfE. 2016. "Further education teacher training: Get into Teaching DfE." DfE, Accessed 26 March 2016. https://getintoteaching.education.gov.uk/explore-my-options/furthereducation-teacher-training.

ETF. 2014. Further Education Workforce Data for England. Edited by Frontier Economics. Accessed 27 March 2016. http://www.et-foundation.co.uk/fe-workforce-data-reports2012-13/: Education \& Training Foundation.

ETF. 2015a. Further Education Workforce Data for England. Edited by Frontier Economics. Accessed 27 March 2016. http://www.et-foundation.co.uk/research/fe-workforcedata-reports-2013-14/

ETF. 2015b. Professional Standards for Teachers and Trainers in Education and Training England. ETF, Accessed 27 March 2016. http://www.etfoundation.co.uk/supporting/support-practitioners/professional-standards/:

Evett, Julie. 2002. Becoming a Secondary Head Teacher. London: Bloomsbury.

Forrest, Colin. 2015. "Inspection and improvement in three further education colleges." Research in Post-Compulsory Education 20 (3):296.

Hodkinson, Phil, Graham Anderson, Helen Colley, Jenny Davies, Kim Diment, Tony Scaife, Mike Tedder, Madeleine Wahlberg, and Eunice Wheeler. 2007. "Learning Cultures in Further Education." Educational Review 59 (4):399-413. doi: $10.1080 / 00131910701619290$.

Independent. 2015. Cuts could see closure of four in ten six form and further-education colleges. The Independent, Accessed 31 March 2016.

http://www.independent.co.uk/news/education/education-news/education-fundingcuts-could-see-closure-of-four-in-ten-six-form-and-further-education-collegesa6727816.html

Lambert, Steve. 2012. "The perception and implementation of sustainable Leadership strategies in further education colleges." Journal of Leadership Education 11 (2):102.

Leader, Gillian. 2004. "Further Education Middle Managers." Educational Management Administration \& Leadership 32 (1):67-79. doi: 10.1177/1741143204039300. 
Lucas, Norman. 2013. "One step forward, two steps back? The professionalisation of further education teachers in England." Research in Post-Compulsory Education 18 (4):389.

Lucas, Norman, Tony Nasta, and Lynne Rogers. 2012. "From fragmentation to chaos? The regulation of initial teacher training in further education." British Educational Research Journal 38 (4):677.

NAO. 2016. Training New Teachers. National Audit Office.

O'Leary, Matt, and Rob Smith. 2012. "Earthquakes, cancer and cultures of fear: qualifying as a Skills for Life teacher in an uncertain economic climate." Oxford Review of Education 38 (4):437-454. doi: 10.1080/03054985.2012.710545.

Orr, Kevin, and Robin Simmons. 2010. "Dual identities: the in-service teacher trainee experience in the English further education sector." Journal of Vocational Education \& Training $62(1): 75$.

Page, Damien. 2013a. "Managers coping in further educational colleges." Journal of Management Development 32 (7):705.

Page, Damien. 2013b. "Recruitment and Transition of Construction Lecturers in Further Education: The Perspective of Middle Managers." Educational Management Administration \& Leadership 41 (6):17.

Purvis, June. 1973. "Schoolteaching as a professional career." British Journal of Sociology $24(1): 43$.

Saunders, Mark, Phillip Lewis, and Adrian Thornhill. 2007. Research Methods for Business Students (4th Ed.). Essex: Prentice Hall.

Sikes, P, L Measor, and P Woods. 1985. Teaching Careers. Vol. 5: Falmer Press.

Simmons, Robin, and Ron Thompson. 2008. "Creativity and performativity: the case of further education." British Educational Research Journal 34 (5):601-618. doi: 10.1080/01411920802223974.

Thompson, Carol, and Peter Wolstencroft. 2015. "Promises and lies: An exploration of curriculum managers' experiences in FE." Journal of Further \& Higher Education 39 (3):399.

Walsh, Patrick. 2006. "Narrowed Horizons and the Impoverishment of Educational Discourse: Teaching, Learning and Performing under the New Educational Bureaucracies." Journal of Education Policy 21 (1):95-117.

Weston, David. 2013. "The future of career progression in teaching." The Guardian, Accessed 20 March 2016. http://www.theguardian.com/teacher-network/teacherblog/2013/may/01/professional-development-future-of-teaching 